\title{
UFPR
}

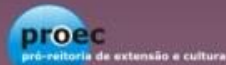

\section{REDE DE DIVULGAÇÃO E POPULARIZAÇÃO DE CIÊNCIA, TECNOLOGIA \& INOVAÇÃO (CT\&I) NO EXTREMO SUL GAÚCHO ${ }^{1}$}

\section{NETWORK DISSEMINATION AND POPULARIZATION OF SCIENCE, TECHNOLOGY \& INNOVATION (STI) IN THE SOUTHERN BRASIL ${ }^{1}$}

\author{
Roberta Chiesa Bartelmebs², João Alberto da Silva ${ }^{3}$
}

${ }^{1}$ Aceito para Publicação no $2^{\circ}$ Semestre de 2016

2Doutoranda em Educação em Ciências e Matemática. Professora na Universidade Federal do Paraná- UFPR- Setor Palotina; betachiesa@gmail.com

${ }^{3}$ Professor Dr. Adjunto no Instituto de Educação da Universidade Federal do Rio Grande. Coordenador do Núcleo de Estudos em Epistemologia e Educação em Ciências; joaosilva@furg.br

\section{Resumo}

Neste trabalho apresentamos a proposta de intervenção do projeto de extensão Rede de divulgação e popularização de Ciência, tecnologia \& inovação (Ct\&l) no extremo Sul gaúcho, contemplado no Edital PROEXT 2013. O projeto prevê ações nos campos da popularização das Ciências Naturais; divulgação da produção científica e tecnológica; promoção do conhecimento científico, e também teve atuação na educação não formal, por meio da educação financeira eeducação alimentar.Em geral, os benefícios científicos e tecnológicos são considerados como um privilégio de poucos, deixando à margem grande parte da população. Compreender a ciência, a tecnologia e a inovação como foco da extensão para inclusão social é um campo inovador e ainda pouco reconhecido devido ao seu ineditismo, ainda que os avanços científicos e tecnológicos sejam direito universal e alienável de todos os seres humanos.

Palavras-Chave: Popularização da Ciência, Divulgação da Ciência, Inclusão social, Redes em CT\&I. 


\section{Abstract}

In this work, we presented the project of network dissemination and popularization of science, technology \& innovation (STI) in the southern Brazil, as set out in Public Notice PROEXT 2013. The project included actions in the fields of popularization of Natural Sciences; dissemination of scientific and technological production; promotion of scientific knowledge, and had operations in non-formal education through the financial education and nutrition education. In general, the scientific and technological benefits are regarded as a privilege of a few, leaving aside much of the population. Understand the science, technology and innovation focused on the extent to social inclusion is an innovative field and still not recognized because of its novelty, although the scientific and technological advances are universal and inalienable right of all human beings.

Keywords: Popularization of the Science, Dissemination of the Science, Social Inclusion, Network in STI.

\section{Introdução}

O projeto de extensão: Rede de divulgação e popularização de Ciência, Tecnologia \& Inovação (CT\&I) no extremo sul gaúcho, foi contemplado em um edital do PROEXT do ano de 2013. A maioria das ações, no entanto, ainda não puderam ser desenvolvidas por conta da liberação dos recursos e da compra dos materiais necessários para sua execução. Neste sentido, este artigo tem como objetivo explicitar a fundamentação teórica da proposta bem como apresentar as ações a serem desenvolvidas dentro das ações da Rede.

Participaram da construção do projeto, 11 alunos de graduação com bolsa de extensão e 3 alunos de pós-graduação. Além disso, o projeto contou com a participação de técnicos-administrativos da Universidade, bem como com a colaboração de professores de outras Instituições de Ensino Superior envolvidas em ações extensionistas.

A Rede de divulgação e popularização de Ciência, Tecnologia \& Inovação (CT\&I) no extremo sul gaúcho tem como princípio norteador a 
Indissociabilidade entre ensino, pesquisa e extensão. Os principais objetivos a que o projeto de dedica são: A inclusão social por meio da ciência; a compreensão do analfabetismo científico e exclusão social e a reflexão sobre o papel da Universidade no desenvolvimento regional.

Apresentaremos inicialmente as reflexões teóricas da proposta, buscando enfatizar o tripé ensino, pesquisa e extensão, que constitui o eixo articulador entre a Universidade e a comunidade da qual faz parte. Posteriormente, detalharemos as atividades vinculadas ao projeto, e por fim, apresentaremos algumas considerações acerca das potencialidades da execução dessa proposta dentro do universo social no qual está inserida.

\section{Indissociabilidade entre ensino, pesquisa e extensão}

O papel social da Universidade tem íntima relação com o desenvolvimento pleno da região na qual está localizada. Não é possível pensar a Universidade restritamente como espaço de produção de conhecimento acadêmico-científico. É preciso extrapolar seus muros e voltarse para a comunidade dando-lhe suporte e devolvendo os resultados das pesquisas e inovações criadas dentro dos laboratórios e salas de aulas das Instituições de Ensino Superior.

A Constituição Federal de 1988 em seu artigo 207 reconhece a importância da extensão universitária colocando-a no mesmo patamar do ensino e da pesquisa, fazendo a seguinte afirmação:

As universidades gozam de autonomia didático-científica, administrativa e de gestão financeira e patrimonial, e obedecerão ao princípio de indissociabilidade entre ensino, pesquisa e extensão (BRASIL, 1988).

Historicamente, sempre houveram distâncias entre o ideal e o executado na extensão. Segundo Freire (2006) a extensão universitária nasce em meados do século XIX na Inglaterra. Em seu momento inicial, surge ignorando quaisquer saber popular, revelando-se como a única depositária de conhecimento válido. Assim, não havia a troca necessária entre a comunidade universitária e a sociedade. De certa forma a Universidade, fechando-se para o 
saber popular e cultural de seu entorno, mantém a relação opressor - oprimido (FREIRE, 1987), cultivada por outros setores da sociedade. Um importante marco para o reconhecimento dos saberes que se constroem fora do âmbito universitário foi a tomada da Universidade Católica em Córdoba (1918) pelos estudantes, trazendo à tona uma nova forma de desenvolvimento da extensão no mundo, uma vertente mais social, tida como "voluntária"(ROCHA, 2001).

No Brasil, a ação extensionistas teve seu início nas Escolas de Agricultura e Veterinária, em Viçosa na década de 1920 (BRASIL, 2012). Ao final da década de 1960 a União Nacional dos Estudantes organizou movimentos culturais e políticos, segundo os quais se partia da premissa do compromisso social da Universidade. Assim passou-se a buscar "uma atuação interprofissional, por meio de metodologias que possibilitavam a reflexão sobre sua prática" (Idem, p. 7). Dessa maneira, o movimento estudantil deu margens a institucionalização da Extensão Universitária. Mesmo em tempos de ditadura militar, algumas ações foram desenvolvidas no sentido de levar a comunidade acadêmica até o campo, com projetos como o Centro Rural de Treinamento e Ação Comunitária (CRUTAC) e do Projeto Rondon, vigente até os dias atuais sob novas roupagens.

Após a promulgação da Lei Básica da Reforma Universitária (Lei n. 5.540/68), estabeleceu-se que:

As universidades e as instituições de ensino superior estenderão àcomunidade, sob a forma de cursos e serviços especiais, as atividades de ensino e os resultados dapesquisa que the são inerentes (Artigo 20) e instituiu a Extensão Universitária (Idem, p. 7).

Posteriormente, sob a influência das ideias de Paulo Freire, a Extensão Universitária passou a ser reconhecida como uma "ação institucional voltada para oatendimento das organizações e populações, com um sentido de retroalimentação e troca de saberesacadêmico e popular" (Idem).

Atualmente no Brasil, a Extensão Universitária é defendida no Plano Nacional de Extensão Universitária que é composto pelos seguintes objetivos:

- Reafirmar a extensão universitária como processo acadêmico definido e efetivado em função das exigências da realidade, indispensável na formação do aluno, na qualificação do professor e no intercâmbio com a sociedade; 
- Assegurar a relação bidirecional entre a universidade e a sociedade, de tal modo que os problemas sociais urgentes recebam atenção produtiva por parte da universidade;

- Dar prioridade às práticas voltadas para o atendimento de necessidades sociais emergentes como as relacionadas com as áreas de educação, saúde, habitação, produção de alimentos, geração de emprego e ampliação de renda;

- Estimular atividades cujo desenvolvimento implique relações multi, inter e/ou transdisciplinares e interprofissionais de setores da universidade e da sociedade;

- Enfatizar a utilização de tecnologia disponível para ampliar a oferta de oportunidades e melhorar a qualidade da educação, aí incluindo a educação continuada e a distância;

- Considerar as atividades voltadas para o desenvolvimento, produção e preservação cultural e artística como relevantes para a afirmação do caráter nacional e de suas manifestações regionais;

- Inserir a educação ambiental e desenvolvimento sustentado como componentes da atividade extensionista;

- Valorizar os programas de extensão interinstitucionais, sob a forma de consórcios, redes ou parcerias, e as atividades voltadas para o intercâmbio e a solidariedade internacional;

- Tornar permanente a avaliação institucional das atividades de extensão universitária como um dos parâmetros de avaliação da própria universidade;

- Criar as condições para a participação da universidade na elaboração das políticas públicas voltadas para a maioria da população, bem como para se constituir em organismo legítimo para acompanhar e avaliar a implantação das mesmas;

- Possibilitar novos meios e processos de produção, inovação e transferência de conhecimentos, permitindo a ampliação do acesso ao saber e o desenvolvimento tecnológico e social do país (BRASIL, 2012, p. 5-6).

Evidencia-se a importância da extensão universitária como eixo articulador entre as atividades de ensino e de pesquisa, bem como apresentase como potencial desenvolvedor de projetos interinstitucionais com colaboração entre universidades brasileiras e estrangeiras.

Desde a consolidação das Instituições de Ensino Superior no país, temse buscado ampliar os horizontes educacionais para além da formação estritamente profissional. Como já defenderam os pioneiros da Educação Nova através do Manifesto redigido em 1932 (AZEVEDO, TEIXEIRA, LOURENÇO FILHO, 1932), a educação superior precisa levar a cabo investigações em todas as áreas do conhecimento, transmiti-los aos estudantes e popularizá-los entre a sociedade. É nesse sentido que se consolida o princípio da indissociabilidade (TAUCHEN, 2009) entre Ensino, Pesquisa e Extensão na Universidade, especialmente na Graduação, entendendo esse espaço como importante coadjuvante na transformação social através da pesquisa, do ensino e das atividades extensionistas. 
No atual momento político e social de nosso país, entendemos que a extensão universitária tem contribuído não apenas para o entendimento da realidade, mas também com sua transformação. A história da Universidade segue construindo novas fronteiras e novos olhares para a sociedade na qual estamos inseridos. Como já afirmava Anísio Teixeira (1964, s/p): "a história de todos os países que floresceram e se desenvolveram é a história da sua cultura e a história da sua cultura é, hoje, a história das suas universidades".

\section{O papel social da extensão em ciência, tecnologia e inovação}

Ainda que com significativas melhorias, o Brasil ainda possui altos índices de desigualdade social. Segundo pesquisa realizada pelo Ministério da Ciência e Tecnologia, 96\% da população brasileira diz nunca ter visitado museus, centros de Ciências, planetários, observatórios, etc. (ABCMC, 2010). O crescimento econômico e o desenvolvimento da Ciência, Tecnologia \& Inovação (C,T\&l) perde seu efeito se não consegue gerar benefícios à população em geral. Dessa forma cria-se um novo tipo de analfabetismo, o "analfabetismo científico" (AULER, DELIZOICOV, 1999), e uma nova forma de segregação e marginalização social.

O termo alfabetização, segundo Paulo Freire $(2006$, p. 8) muito mais do que ler palavras, precisa: "propiciar a 'leitura do mundo' Leitura da palavra e 'leitura do mundo' devem ser consideradas numa perspectiva dialética Alfabetizar não é apenas repetir palavras, mas dizer a sua palavra". Nesse sentido, o termo alfabetização é concebido para além da simples aquisição de um sistema de signos (o alfabeto).

Sua compreensão de alfabetização como sendo a possibilidade de leitura de mundo, mas não uma leitura isenta de opinião, uma leitura crítica e criativa do mundo, inspira autores da área da Educação em Ciências como Auler e Delizoicov (2001). Para esses autores, com relação ao termo alfabetização, tal como cunhado por Freire, ao ser utilizado para referir-se à ciência e tecnologia deve levar em conta:

Uma reinvenção da concepção freireana deve incluir uma compreensão crítica sobre as interações entre Ciência, Tecnologia e 
Sociedade (CTS), dimensão fundamental para essa 'leitura do mundo' contemporâneo Um avanço para além de Freire, tendo-o como inspirador (grifos dos autores, AULER e DELIZOICOV, 2001, p 23).

Ou seja, não se trata apenas de apropriar-se do termo cunhado por Freire, mas de partindo dele inspirar-se para construir uma definição para a alfabetização científica e tecnológica. Nesse sentido, há uma ideia "prática" para a popularização das ciências, pois é a possibilidade de se conhecer os produtos e os processos científicos e tecnológicos, tornando os cidadãos sujeitos capazes de compreenderem o mundo que os cerca e do qual fazem parte ativamente.

A divulgação científica e a alfabetização científica desempenham importante papel de socializador do conhecimento, bem como permitem a aproximação da comunidade com a $(C, T \& l)$ produzidas no país. A alfabetização científica, bem como a divulgação científica, pode ser compreendida como meio de inclusão social visto que colabora com a ampliação do conceito de cidadania dos sujeitos envolvidos.

Com relação à inclusão social por meio da Ciência, um de seus aspectos consiste em:

\footnotetext{
Possibilitar que cada brasileiro tenha a oportunidade de adquirir conhecimento básico sobre a ciência e seu funcionamento que lhe dê condições de entender o seu entorno, de ampliar suas oportunidades no mercado de trabalho e de atuar politicamente com conhecimento de causa (MOREIRA, 2006, p. s/p).
}

Assim, o projeto Rede de divulgação e popularização de Ciência, Tecnologia \& Inovação (CT\&l) no extremo sul gaúcho foi constituído, visando impactar positivamente no auxílio à formação do cidadão mais consciente e consequentemente mais atuante na sociedade que o cerca.

\section{O ensino de ciências no Brasil e o papel da Extensão Universitária neste cenário}

Segundo Waiselfisz (2009), o ensino de Ciências, era apresentado de forma restrita em nosso país. Parcelas limitadas da população trabalhavam temas ligados à Ciências de forma mais profunda, em uma realidade na qual a 
grande parte dos alunos era preparada apenas para o mercado de trabalho. Hoje vivemos em um mundo intitulado de "sociedade da informação" (WERTHEIN, 2000), mas até que ponto essa sociedade tem se apropriado do seu conhecimento?

O Instituto de Pesquisa Econômica Aplicada (IPEA) afirma que a educação no Brasil apresenta um atraso de uma década com relação a países com o mesmo padrão de desenvolvimento. Em 2006, a Organização para a Cooperação e Desenvolvimento Econômico (OCDE) realizou o exame do Programa Internacional de Avaliação de estudantes (PISA) com enfoque nas Ciências, o qual nos apresentou dados que confirmam a existência de um déficit no ensino. O Brasil figurou entre os últimos lugares com relação aos demais países participantes da avaliação.

Segundo os dados do PISA (WAISELFISZ, 2009), os estudantes brasileiros, concluintes do Ensino Fundamental, em sua maioria situam-se entre o nível $1(34,1 \%$ ) e $0(27,8 \%$ ) de proficiência em ciências (o que equivale ao termo letramento ou alfabetização científica, que logo mais discutiremos). A classificação nesses níveis (que vão do 0 ao 6) se realiza levando em conta as seguintes habilidades esperadas dos estudantes (Idem, p14):

1. Identificar os assuntos científicos. Implica reconhecer os tópicos factíveis de serem pesquisados cientificamente e reconhecer os rasgos fundamentais de uma investigação científica;

2. Explicar cientificamente os fenômenos. Capacidade de aplicar os conhecimentos da ciência a situações concretas. Implica descrever ou interpretar os fenômenos cientificamente e prever mudanças, assim como identificar as descrições, explicações e predições apropriadas;

3. Usar a evidência científica Habilidade para interpretar evidências, tirar conclusões e comunicá-la. Identificar as hipóteses, as evidências e os processos subjacentes às conclusões. Reconhecer as implicações sociais do desenvolvimento científico e tecnológico.

Os dados emergentes revelam, para nós brasileiros, um problema preocupante: Nossos jovens estudantes, concluintes do Ensino Fundamental não estão construindo, ao longo de oito anos competências e habilidades suficientes para reconhecerem no dia a dia a presença dos conceitos científicos e tecnológicos que certamente estudam na disciplina de Ciências.

Podemos compreender que uma pessoa alfabetizada cientificamente, (AULER, DELIZOICOV, 2001, s/p): 
Entende que a sociedade controla a Ciência e a Tecnologia (CT) através de alocação de recursos; Usa os conceitos, habilidades e valores científicos para tomar decisões cotidianas; Reconhece as limitações e as utilidades da (CT) para o progresso da humanidade; Sabe e utiliza os principais conceitos, hipóteses e teorias da ciência; Distingue entre evidencias científicas e opiniões pessoais; Tem uma visão mais rica do mundo, resultado da educação científica; Conhece fontes confiáveis de informações (CT) utilizando-as em processos de tomada de decisões.

Ou seja, compreende os processos científicos e tecnológicos e é capaz de julgar situações em que o uso da ciência ou da tecnologia se apresentam. São conhecimentos que podem ser construídos também em outros espaços educativos não-escolares.

\section{Previsão das ações do projeto}

Como citado anteriormente, o projeto tem como objetivo principal implantar e consolidar uma Rede de ações de divulgação, popularização e disseminação de Ciência, Tecnologia \& Inovação (CT\&l), focando-se na alfabetização científica, na promoção da equidade social e do acesso à informação. Seu público alvo será constituído por moradores de periferia e zona rural, do extremo sul gaúcho, além da comunidade acadêmica, a fim de promover inclusão social através da difusão do conhecimento cientifico e tecnológico.

Em resumo, as ações previstas para o projeto são: (a) popularização das Ciências Naturais, com observaçõesastronômicas, visitas a laboratórios e centros de Ciências, construção de coleções biológicas, por meio dataxidermia, para viabilização à visitação de deficientes visuais (b) divulgação da produção científica etecnológica, através de programas de TV, rádio e de canais de vídeo na internet, e (c) promoção doconhecimento científico, através de oficinas de uso de instrumentos e métodos científicos e tecnológicostais como robótica, etc.., e (d) atuando na educação não formal, por meio da educação financeira eeducação alimentar.

\section{Detalhamento das ações a serem realizadas}


Apresentamos a seguir um resumo de cada uma das atividades vinculadas ao projeto, que serãodesenvolvidas no decorrer do ano de 2016 e 2017. As ações estão sob a coordenação de um professor, colaborador do projeto, de dois ou mais bolsistas de extensão, que serão contemplados com a bolsa PROEXT 2013, e também de alunos da pós-graduação, orientandos dos professores ligados a proposta.

Ações para captação de jovens talentos para engenharias e computação

Promoção de atividades em escolas e na comunidade para introduçãoda robótica com crianças e ações de programação a fim de captanear futurosquadros para áreas de engenharia e computação. Serão oferecidas oficinas de programação e robótica com os kits TOPOBO, para alunos das escolas públicas de Ensino Médio, bem como para as escolas técnicas do município e Região.

A ciência em suas mãos: ações para inclusão de pessoas com deficiência visualem popularização das Ciências

Visitação monitorada de pessoas com deficiência visual, e videntes (queserão privados deste sentido) com o objetivo de conhecer espécimes animaistaxidermizadas. Serão priorizados animais que componham a fauna do ecossitema costeiro do Sul do país. Além disso, serão oferecidas, nessas visitações, oficinas de conscientização ambiental com palestras e atividades lúdicas que tratem do tema da preservação da biossistema costeio sul-riograndense.

Alfabetização alimentar: uma alimentação equilibrada e saudável é possível?

Refletir a respeito das relações de produtos alimentícios consumidos eas necessidades diárias de cada pessoa para obtenção de uma alimentaçãosaudável. Oficinas desenvolvidas nas escolas de Educação do 
Campo de municípios do extremo sul gaúcho, com a finalidade de refletir também, acerca da produção orgânica de alimentos, e enfatizar a importância da agricultura familiar para a produção de alimentos saudáveis, enfatizando assim uma alimentação equilibrada e consciente.

Canal Ciência, Tecnologia \& Inovação (CT\&l)

Criação de um programa a ser divulgado na rádio e TV da Universidade, bem como um canal do Youtube. O objetivo principal é a promoção e divulgação de Ciência, com entrevistas, experimentoscientíficos, promovendo a interação entre universidade-comunidade. Osprogramas serão elaborados e gravados no espaço da Universidade da qual o projeto é vinculado, bem como de outras instituições de Ensino Superior e em espaçoscoletivos da cidade. Cada programa terá a duração deaproximadamente 45 minutos, com apresentação de um programa mensal,totalizando 12 programas ao todo, com total de 9 horas de programação.

Educação financeira e uso de tecnologias

Promoção de atividades de educação financeira com crianças eadultos. Elaboração de oficinas didáticas em escolas e Ensino Fundamental, envolvendo alunos, professores e responsáveis. Construção de jogos e material didático-pedagógico para implantação da Educação financeira nas escolas da Rede Pública.

Visitação às coleções biológicas do Centro de Estudos Ambientais, Ciências eMatemática (CEAMECIM) e ao laboratório de Matemática e Física (LEMAFI)

Proporcionar conhecimento e interação do laboratório de matemática eda coleção biológica do CEAMECIM a alunos, professores e comunidade escolar(pais, responsáveis) dos anos iniciais da rede municipal de ensino, através davisitação e práticas pedagógicas a serem realizadas no ambiente do laboratórioeCEAMECIM. Serão também, oferecidas oficinas didáticas com o 
uso dos laboratórios do CEAMECIM, para fomentar a integração entre Universidade e escola.

\section{Curso de Extensão Ensino de Astronomia}

O Curso de Astronomia Básica para o Ensino Fundamental tem como objetivo geral popularizar a astronomia e seu ensino entre professores e futuros professores de ciências no Ensino Fundamental, com base numa perspectiva epistemológica construtivista.Além do curso, serão oferecidos mensalmente, atividades de observação do céu noturno em espaços coletivos da cidade e do campo, especialmente em escolas públicas, feiras e coletivos dos municípios do extremo Sul gaúcho.

Semana Nacional da Ciência, Tecnologia \& Inovação

Ações de divulgação científica envolvendo as atividades anteriormente citadas, na comunidade acadêmica e seu entorno através de mini-cursos, palestras e atividades em escolas e espaços públicos como praças, feiras e eventos.

\section{Metodologia e Avaliação do Projeto Rede de divulgação e popularização de Ciência, Tecnologia \& Inovação (CT\&I) no extremo sul gaúcho}

Uma das estratégias da Rede é a construção de comunidades aprendentes para o desenvolvimento das ações previstas dentro do projeto. $O$ conceito de Comunidade de Prática foi desenvolvido por Lave e Wenger (1998). Segundo Wenger:"Comunidades de Prática são grupos de pessoas que compartilham um interesse ou paixão por alguma coisa que eles fazem e aprendem a fazê-lo melhor ao interagirem regularmente" (2008). As comunidades de prática podem estar presentes em todos os ambientes da sociedade, seja em uma associação, seja em uma escola ou mesmo em uma feira de livros. 
Para um grupo poder se configurar em uma Comunidade de Prática, precisa necessariamente compartilhar algo que diga respeito a todos os participantes. A aprendizagem, no entanto, pode não ser o objetivo final destes grupos, mas ocorrerá no decorrer das atividades deste.

O pressuposto epistemológico das Comunidades de Prática parte da ideia de que a aprendizagem se dá enquanto participação social, isto é, o sujeito como participante ativo nas práticas das comunidades sociais construindo identidade com relação a essas comunidades.

Neste sentido, é possível pensar que um grupo de professores, pesquisadores, acadêmicos e ou moradores de uma comunidade, que se reúne para realizar uma atividade, possa ser também uma Comunidade de Prática, na medida em que seus saberes serão tecidos em discursos coletivos, construindo ereconstruindo significados para suas práticas, seus saberes e suas teorias. Para Wenger (2008, p. 73), épreciso que a prática seja o recurso de coerência de uma comunidade, isto é, que respeite três dimensõesdesta relação: Que seja um engajamento mútuo e um empreendimento conjunto, e que, por fim, constitua

repertórios compartilhados.

Uma Comunidade de Prática é o que o autor chama originalmente de joint enterprise. A expressãopressupõe a ideia de um empreendimento conjunto, no coletivo. Wenger (Idem, p. 77) explica que, na suaconcepção de comunidade, não basta que os membros ocupem um mesmo espaço físico, como umacomunidade de um bairro, como no exemplo citado acima. É preciso que compartilhem algo para além dolocal físico. Esse empreendimento é "resultado de um processo coletivo de negociação que reflete acomplexidade que é o envolvimento mútuo", ou seja, uma comunidade cria laços de responsabilidade

entre os participantes, porque estão todos comprometidos com uma atividade compartilhada. Podemostornar esse empreendimento coletivo em uma estratégia de aprendizagem, podemos fazer da comunidadede prática uma comunidade aprendente.

A avaliação do projeto ocorrerá ao longo do desenvolvimento das suas etapas. Prevemos a realização de reuniões sistemáticas com aequipe, de 
modo que todos os envolvidos, comunidade interna e externa, possam dialogar com a proposta do projeto. Assim, a avaliação será contínua e qualitativa.A cada atividade realizada, os participantes serão convidados a avaliarem as estratégias utilizadas, o material e também a atuação dos monitores envolvidos nas ações. Dessa forma, pretende-se criar uma cultura de avaliação permanente da proposta, a fim de potencializar mudanças para futuros projetos a serem desenvolvidos a partir da $\mathrm{A}$ Rede de divulgação e popularização de Ciência, Tecnologia \& Inovação (CT\&l) no extremo sul gaúcho.

\section{Considerações Finais}

A articulação de propostas de extensão em rede vinculadas a grupos de pesquisa permite um aprofundamento da interlocução da extensão com 0 ensino e a pesquisa. No campo da divulgação e promoção das ciências, esse elemento agrega maior destaque. A apresentação de ações extensionistas integradas permite um maior envolvimento dos bolsistas em diferentes frentes de trabalho, bem como amplia o impacto junto às comunidades atendidas.

Por isso, entendemos que o projeto de extensão Rede de divulgação e popularização de Ciência, Tecnologia \& Inovação (CT\&l) no extremo sul gaúcho, tem um grande potencial formativo para a comunidade que será envolvida nas suas ações. Além da promoção da ciência e tecnologia, a alfabetização científica será promovida de forma a agregar comunidade, escola e Universidade.

Em geral, os benefícios científicos e tecnológicos são poucoassociadoàs camadas populares, sendo considerados um privilégio de classes mais elevadas. Compreender a ciência, a tecnologia e a inovação como foco da extensão para inclusão social é um campo inovador e ainda pouco reconhecido devido ao seu ineditismo, ainda que os avanços científicos e tecnológicos sejam direito universal e alienável de todos os seres humanos.

\section{Referências}


ABCMC, ASSOCIAÇÃO BRASILEIRA DE CENTROS E MUSEUS DE CIÊNCIA - ABCMC. Programa nacional Pop Ciência 2022 (2010). Disponível em: $<$ http://www.abcmc.org.br/publique1/media/POPCienciaBrasil2022_versao2.pdf >. Acesso em Ago, 201

AULER, Decio; DELIZOICOV, Demétrio. Alfabetização científico-tecnológica para quê? In: Ensaio Pesquisa em Educação em Ciências. v 3, n 1, Jun. 2001.

AULER, Decio; DELIZOICOV. Demétrio. Visões de Professores sobre as Interações entre Ciência-Tecnologia-Sociedade (CTS). Resumos, II Encontro Nacional de Pesquisa em Educação em Ciências (II ENPEC). Vallinhos, 1999.

AZEVEDO, Fernando; DORIA,Afranio Peixoto A. de Sampaio; TEIXEIRA, AnisioSpinola; LOURENÇO FILHO, M. Bergstrom; PINTO, Roquette; PESSÔA, J. G. Frota; MESQUITA FILHO,Julio de; BRIQUET, Raul; CASASSANTA, Mario; CARVALHO, C. Delgado de; ALMEIRDA JR, A. Ferreira de; FONTENELLE, J. P.; BARROS, Roldão Lopes de; SILVEIRA, Noemy M. da

LIMA, Hermes; VIVACQUA, Attilio; VENANCIO FILHO, Francisco; MARANHÃO, Paulo; MEIRELES, Cecilia; MENDONÇA, Edgar Sussekind de; ALBERTO, Armanda Alvaro; REZENDE, Garcia de; CUNHA, Nobrega da; LEMME, Paschoal; GOMES, Raul.Manifesto dos pioneiros da educação nova, $1932 . \quad$ Disponível em: <http://www.histedbr.fe.unicamp.br/revista/edicoes/22e/doc1_22e.pdf>. Acesso em Ago, 2014.

BRASIL. Constituição Federal de 1988. Brasília, 1988, Artigo 207.

BRASIL. REDE NACIONAL DE EXTENSÃO. Plano Nacional de Extensão Universitária. Disponível em: < http://www.renex.org.br/documentos/ColecaoExtensao-Universitaria/01-Plano-Nacional-Extensao/Plano-nacional-deextensao-universitaria-editado.pdf> Acesso em Ago, 2014.

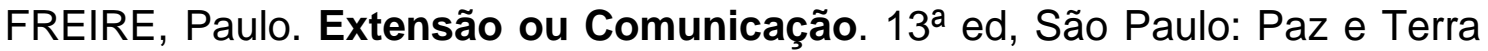
2006.

MOREIRA, Ildeu de Castro. A inclusão social e a popularização da ciência e tecnologia no Brasil. In: Inclusão Social, Brasília, v. 1, n. 2, p. 11-16, abr./set. 2006.

ORGANIZAÇÃO DAS NAÇÕES UNIDAS PARA A EDUCAÇÃO, A CIÊNCIA E A CULTURA - UNESCO. A ciência para o século XXI: uma nova visão e uma base de ação- Brasília: UNESCO, ABIPTI, 2003.

PIMENTA, Selma Garrido; LIMA, Maria Socorro Lucena. Estágio e docência $3^{a}$ Ed. (Coleção docência em formação. Série saberes pedagógicos). São Paulo: Cortez Editora, 2008.

ROCHA, R. M. Gurgel. A Construção do Conceito de Extensão universitária na America Latina In: SOARES, Laura Tavares. (Re) definições das relações da 
Extensão com a Sociedade: a questão da Prestação de Serviços. IN: SESU/MEC VII SEMINÁRIO NACIONAL REUNI, 2013. (PDF) Disponível em: $<$ http://portal.mec.gov.br/dmdocuments/laura_tavares.pdf>. Acesso em Ago. 2014.

TAUCHEN, Gionara. O princípio da indissociabilidade universitária: um olhar transdisciplinar nas atividades de ensino, pesquisa e extensão. Tese doutorado. Doutorado em Educação PUCRS. 2009.

TEIXEIRA, Anísio. A universidade de ontem e de hoje. Revista Brasileira de Estudos Pedagógicos. Rio de Janeiro, v.42, n.95, jul./set. 1964. p.27-47. Disponível em: http://www.bvanisioteixeira.ufba.br/artigos/ontem.html. Acesso em 26 nov. 2013.

WAISELFISZ, JulioJacobo. 0 ensino das ciências no Brasil e o PISA. Sangari do Brasil: São Paulo, 2009.

WENGER, Etienne D. <http://www.ewenger.com> Acesso em: 14 mar. 2011.

WENGER, Etienne D. Communities of practice: learning, meading, and identity. 18th Printing. New York: Cambridge University, 2008.

WERTHEIN, Jorge. A sociedade da informação e seus desafios. In: Ciência da Informação, Brasília, v. 29, n. 2, p. 71-77, maio/ago. 2000. 